\title{
LABOUR MOBILITY AND RETIREMENT
}

Agar Brugiavini, Mario Padula, Giacomo Pasini, Franco Peracchi

๑ Mea-Mannheim Research Institute for the Economics of Aging

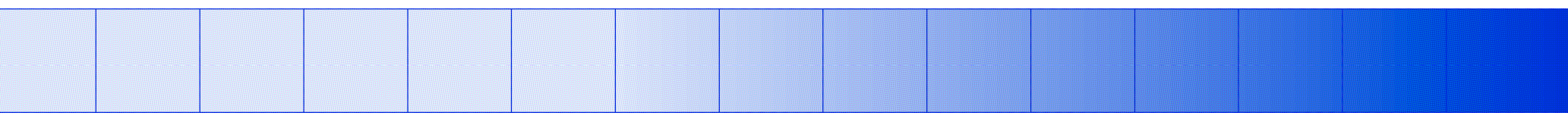

L13, 17_D-68131 Mannheim_Phone +49 621 181-2773/1862_Fax +49 621 181-1863_www.mea.uni-mannheim.de 


\title{
11 Labour Mobility and Retirement
}

\author{
Agar Brugiavini, Mario Padula, Giacomo Pasini and Franco Peracchi
}

\subsection{Work life histories}

Public and private pensions represent the main income source of Europeans in their old age. Pension provisions depend on workers' career: workers retiring under the same pension regime might receive very different pension benefits depending on the time pattern of employment and unemployment spells, on the magnitude and the timing of income shocks and, more generally, on the age-profile of earnings (Boeri and Brugiavini, 2009). Individuals are often induced to retire early, but inadequate contributions due to a short work history may reduce household's welfare later in life (Angelini, Brugiavini and Weber, 2009). Previous work has shown great variability in the patterns of transition from work to retirement (Peracchi and Welch, 1994; Brugiavini and Peracchi, 2005; Brugiavini, Pasini and Peracchi, 2008), yet little is known about how the working history of individuals affects their resources in retirement. This would require panel data where workers are followed over a long period of time. Long panels, however, are hardly available and would be subject to serious problems of attrition and non-response. A simple alternative are cross-sectional data or short panels with a retrospective component, such as SHARE. The SHARELIFE component of this survey provides information on the history of past employment and allows accounting for periods of unemployment during the working life. In this paper we relate incidence and duration of unemployment, as well as tenure in a job, to the replacement rate at retirement. The international comparability of the data provides insights on the effect of labour market institutions and regulation on workers' mobility, and on the insurance properties of social security against earnings risks.

The rest of the paper is organized as follows. Section 11.2 documents the patterns of jobs turnover across European countries. The data show marked differences between Northern and Southern Europe: in Denmark, at one end of the spectrum, the average worker changes six jobs in his working life, in Greece, at the other end of the spectrum, only once. The same number of transitions between jobs during a working life may result in very different contribution histories, depending on the tenure at each job and the duration of unemployment spells between jobs. Therefore, Section 11.3 reviews duration data and, again, provides evidence of a North-South gradient. Job tenure and mobility feed back into replacement rates, which are investigated in Section 11.4. The data reveal smaller cross-country differences in replacement rates, suggesting that the design of social security systems may in fact contribute to attenuate the effect of different career patterns on retirement benefits. Section 11.5 concludes. 


\subsection{Job turnover}

In this section we document the wide variability in working histories of European workers. We start by looking at the number of jobs that individuals held in their life. Figures 11.1a and 11.1b are based on the entire sample and show that women tend to have a lower number of jobs, particularly in Poland and in Southern countries such as Italy, Spain, and Greece. The German sample is split into those who in 1989 were living in East Germany (DE-E) and those who were in West Germany (DE-W). Irrespective of gender, younger cohorts have a higher number of jobs, indicating that mobility between jobs is more common for the younger old. Note that some of the younger old are still working, so that our data may effectively underestimate the degree of labour mobility The gender gap is smaller in Northern than in Southern countries, where female participation is lower. Differences across cohorts are also smaller in Northern countries. The overall picture is one of greater job turnover in Northern countries, where the differences between genders and across cohorts are generally smaller. Depending on the social security system and the pension legislation, higher mobility may be associated with "losses" in terms of pension and social security benefits, for example if pension rights are not fully portable or if changes are associated with long unemployment spells. It should be stressed that mobility per se does not necessarily have a negative effect on pensions, as for example workers may go from a lowpay job to a high-pay job hence increasing their pension levels. It is the existence of distortions in the pension rules (such as lack of portability) which might create these losses in association with mobility (Gustman and Steinmeier, 1993).

Figure 11.1a: Average number of jobs per individual, by gender

Males $\square$ Females

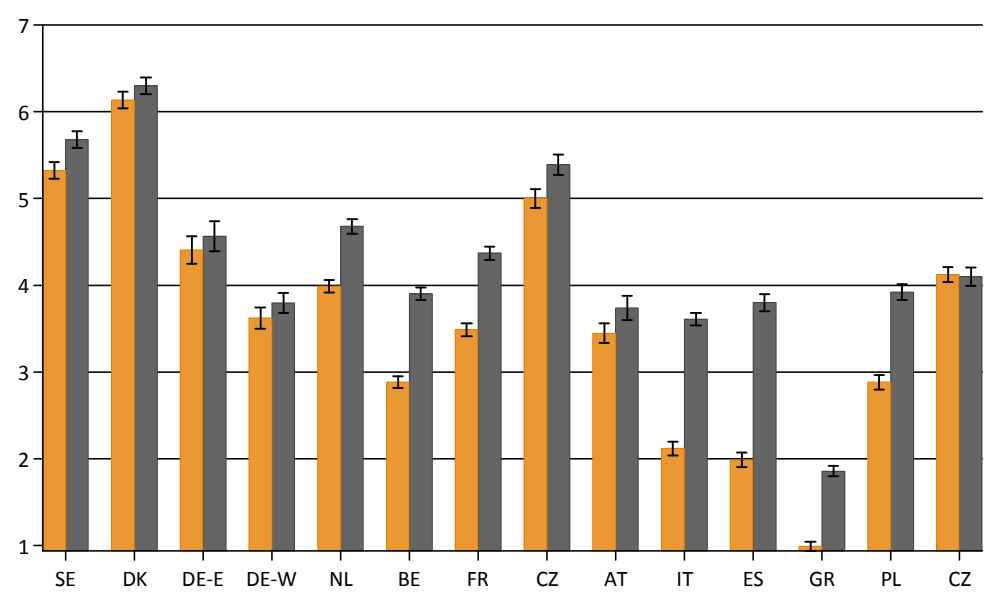


Figure 11.1b: Average number of jobs per individual, by cohort

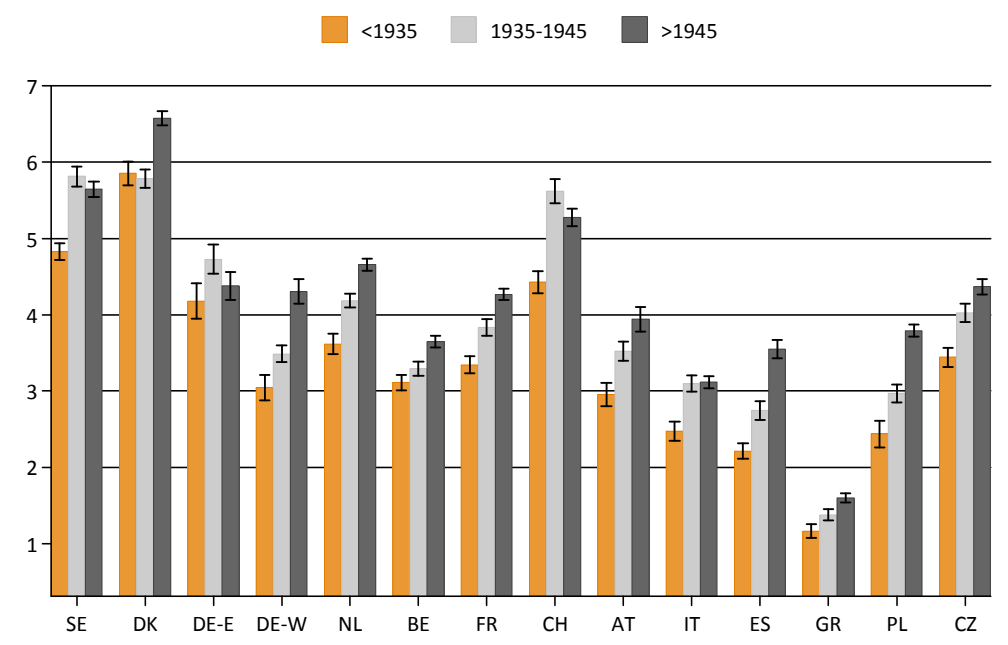

Moreover, even when pension benefits are fully portable, pension income may vary depending on whether job turnover is associated to job-to-job transition or to transition from job to long unemployment spells. Therefore, in Figures 11.2a and $11.2 \mathrm{~b}$ we graph the average number of job changes which resulted in at least 6 months out of employment, again grouping the data by gender and year of birth. The data show differences between countries with Northern countries and East Germany now scoring a higher number of job-to-unemployment transitions compared to Southern European countries. This is particularly true among women, and as a consequence gender differences are wider in Scandinavian rather than Southern countries. Figures $2 \mathrm{a}$ and $2 \mathrm{~b}$ also indicate that most of the job changes during the life span are job-to-job transitions, which are unlikely to imply losses in terms of pension benefits: the average number of changes which involved at least 6 months out of employment is much lower than the average number of jobs per individual.

In terms of gender differences, European countries can be split into two groups. In the first group (Sweden, Denmark, East and West Germany, the Netherlands, Switzerland, Austria and the Czech Republic) women have approximately twice the number of job changes than men, which suggests that women experience many transitions out-of-the-labour-market. In the remaining countries (Italy, Spain, Greece, France, Belgium and Poland) gender differences are smaller. This does not necessarily indicate that labour market conditions for women are better: it is quite likely that in these countries women experience fewer employment episodes, and thus fewer transitions from one job to another. Differences across cohorts are almost not significant in Sweden, while for Spain, at the other end of the spectrum, the average number of job changes which involved more than 6 months out 
of employment is twice as large for the youngest old, as shown in Figure 11.2b. Furthermore, differences across cohorts are larger in figure $11.2 \mathrm{~b}$ than in figure $11.1 \mathrm{~b}$, probably due to changes in the employment protection legislation across cohorts depending on the time of entry to the job market.

Working histories might be similar in terms of job turnover, but very different when it comes to their effects on replacement rates. This depends on the portability of benefits between jobs, but also on average job tenure and the duration of unemployment spells between jobs. We therefore devote the next section to document how job tenure and unemployment duration vary across European countries.

Figure 11.2a: Average number of job changes per individual which entailed 6 months or more out of employment, by gender

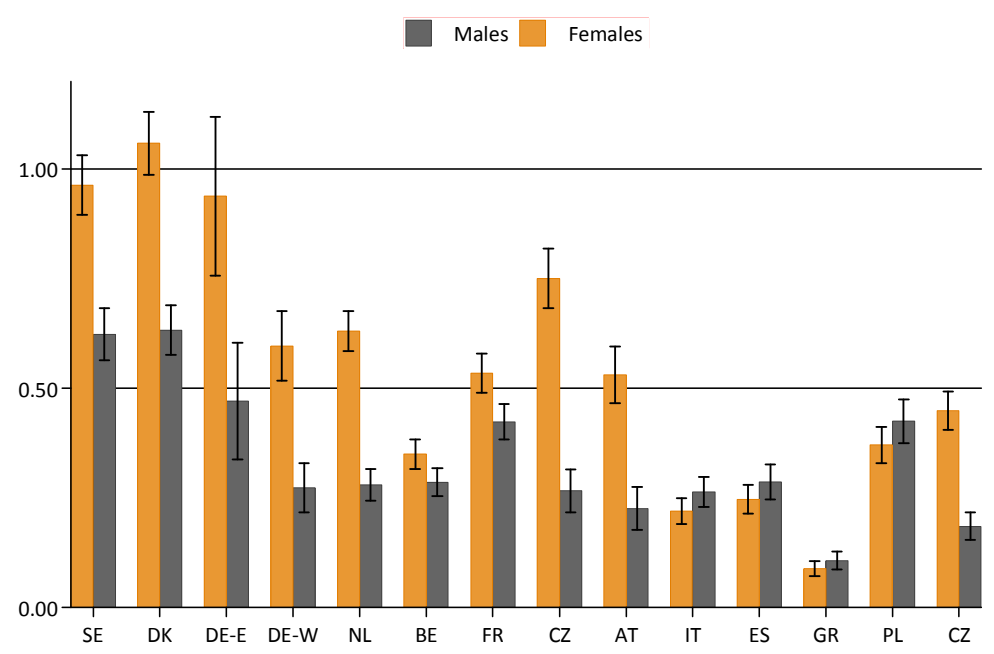

Figure 11.2b: Average number of job changes per individual which entailed 6 months or more out of employment, by cohort 


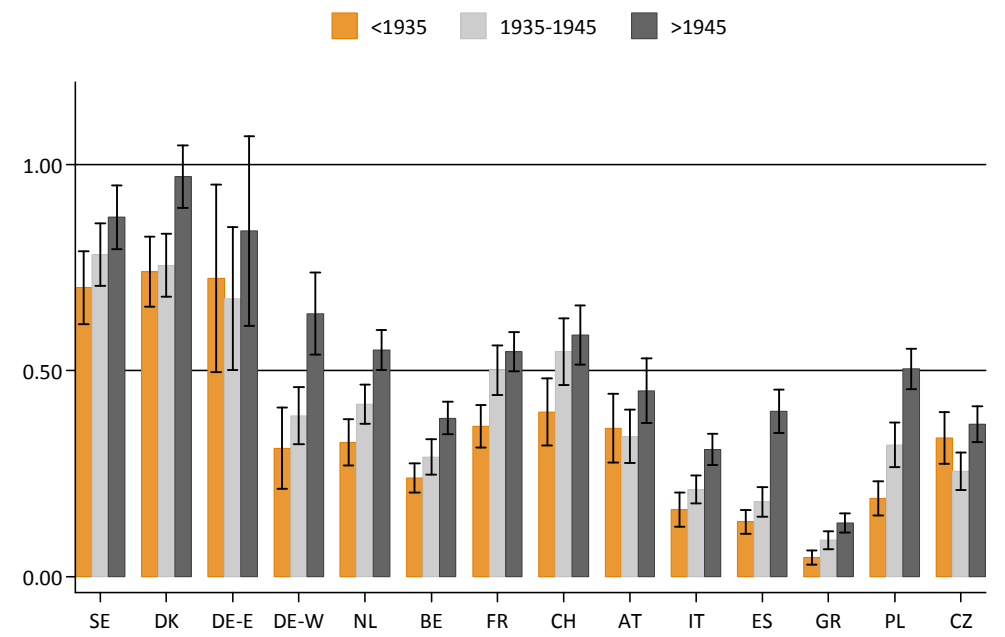

\subsection{Employment and unemployment duration}

The SHARELIFE survey allows us to measure the length of time spent in each specific labour market state, i.e. the duration of the different spells of employment and unemployment. Being more specific, the respondent is asked to report each employment and unemployment episode lasting six months or more. Short employment and unemployment episodes are therefore excluded from our analysis.

Table 11.1 describes the distribution of duration of employment spells lasting at least six months. Therefore, the sample includes all the employments spells of any individual who reported to have worked at least once in his/her life. The distribution is left skewed for all countries, with marked differences across countries: Denmark displays the highest degree of left-skewness, while for Greece the distribution is relatively flat. Jobs at different points in a working life are likely to have different tenures, due to search for a good match at the beginning of the career and job-specific skill acquisition later in life. Since we can observe duration and timing of employment spells over the life cycle, we can study the distribution of employment spell changes between jobs, and in particular between the first job and the last job. The results, which we do not show for brevity, reveal interesting patterns: the distribution of employment duration for the last job is quite even across all European countries. This is perhaps not surprising, if the cost of searching for a good match increases with age at a similar rate across European countries. 
Table 11.1: Percentage distribution of employment duration by country

\begin{tabular}{lrrrr}
\hline & \multicolumn{3}{c}{ Duration in years } & $\begin{array}{r}\text { Number of } \\
\text { observations }\end{array}$ \\
\hline & $0-24$ & $25-34$ & $35+$ & \\
\hline SE & $90.78 \%$ & $5.07 \%$ & $4.15 \%$ & 6,898 \\
DK & $93.90 \%$ & $3.89 \%$ & $2.21 \%$ & 8,669 \\
DE-E & $89.71 \%$ & $5.73 \%$ & $4.56 \%$ & 1,030 \\
DE-W & $84.82 \%$ & $7.86 \%$ & $7.32 \%$ & 2,213 \\
NL & $91.34 \%$ & $5.15 \%$ & $3.51 \%$ & 6,353 \\
BE & $83.18 \%$ & $9.56 \%$ & $7.26 \%$ & 5,994 \\
FR & $87.02 \%$ & $7.96 \%$ & $5.03 \%$ & 6,146 \\
CH & $92.74 \%$ & $4.03 \%$ & $3.24 \%$ & 4,420 \\
AT & $81.70 \%$ & $10.40 \%$ & $7.90 \%$ & 2,481 \\
IT & $80.52 \%$ & $11.51 \%$ & $7.97 \%$ & 4,441 \\
ES & $80.16 \%$ & $8.48 \%$ & $11.36 \%$ & 3,608 \\
GR & $55.47 \%$ & $18.59 \%$ & $25.94 \%$ & 2,340 \\
PL & $81.21 \%$ & $11.31 \%$ & $7.48 \%$ & 4,093 \\
CZ & $77.39 \%$ & $9.62 \%$ & $12.98 \%$ & 4,052 \\
Total & & & & 62,738 \\
\hline
\end{tabular}

It is worth noticing that the fraction of people reporting extremely long employment spells is somewhat higher than expected: $6.64 \%$ of the overall sample of spells lasts 35 years or more, $3.25 \%$ more than 40 years, and $1.21 \%$ lasts more than 45 years. This does not seem to be driven by employment duration of civil servants, which is likely to be on average longer than employment duration of private sector employees: the same table obtained excluding civil servants exhibit the same long right tail. Even after dropping spells longer than 45 years, as they are likely to be outliers, the distribution might give more weight to longer spells than expected, for three reasons: first, since we are dealing with older workers it is common to start working at very young ages and hence it is likely that these generations had long spells. Second as already explained spells shorter than 6 months are not considered, thus reducing the probability mass on the left tail. Third, interviewers were asked to instruct respondents to count short-term jobs which are similar, even if working for different employers, as a single spell and not record changes of job for the same employer as different spells.

Figure 11.3 shows the average duration of long unemployment spells in years. In all countries (except Czech Republic), women experience longer unemployment spells. Looking at the average duration of unemployment spells can however hide important differences between workers, beyond those simply captured by gender. 
Figure 11.3: Average number of years spent in unemployment conditional on having been unemployed

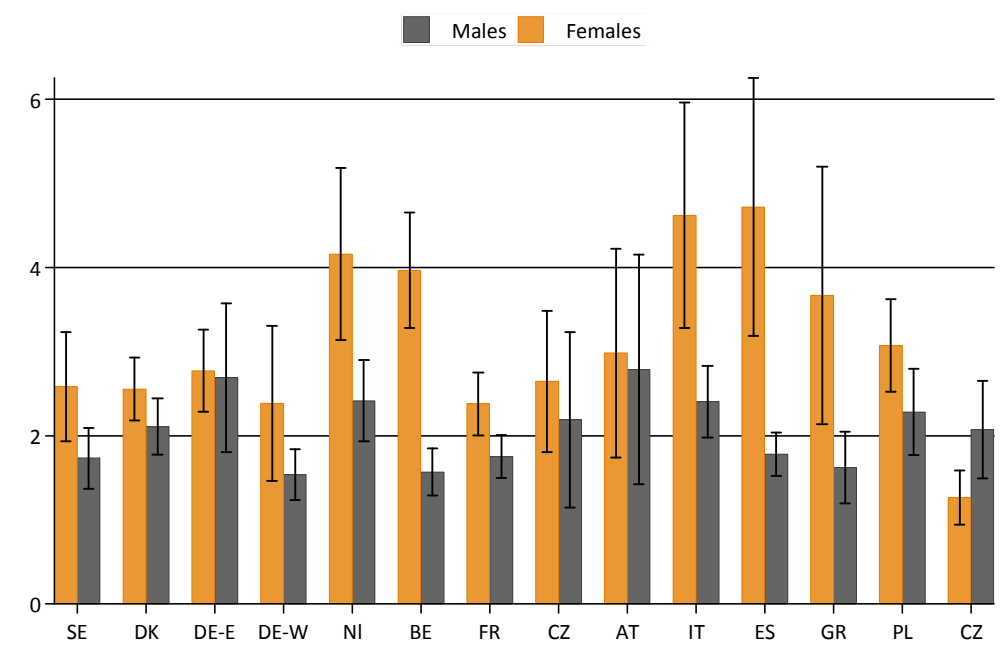

\subsection{Replacement rates}

Depending on the pension regime a person faces at different stages of her life, the sequence of jobs in her work history could be more relevant or less relevant for her pension benefits entitlements and therefore for her replacement rate. In this section, we compute the replacement rate as the ratio of the first benefits received over the last wage in the main job for those respondents who indicate as their main job the one that ended with a transition into retirement. Note that in this way we neglect those who had a secondary job in the last years before retirement, those who chose other pathways to retirement (for example through disability), and those who experienced a long period out of employment before retirement, e.g. women who leave their job to take care of home and family. We also drop the self-employed and focus only on private and public sector employees: rules concerning benefit calculation are quite different for the employees and the selfemployed, and for the latter it is often problematic to relate replacement rates to work histories.

Figure 11.4a: Replacement rate by country 


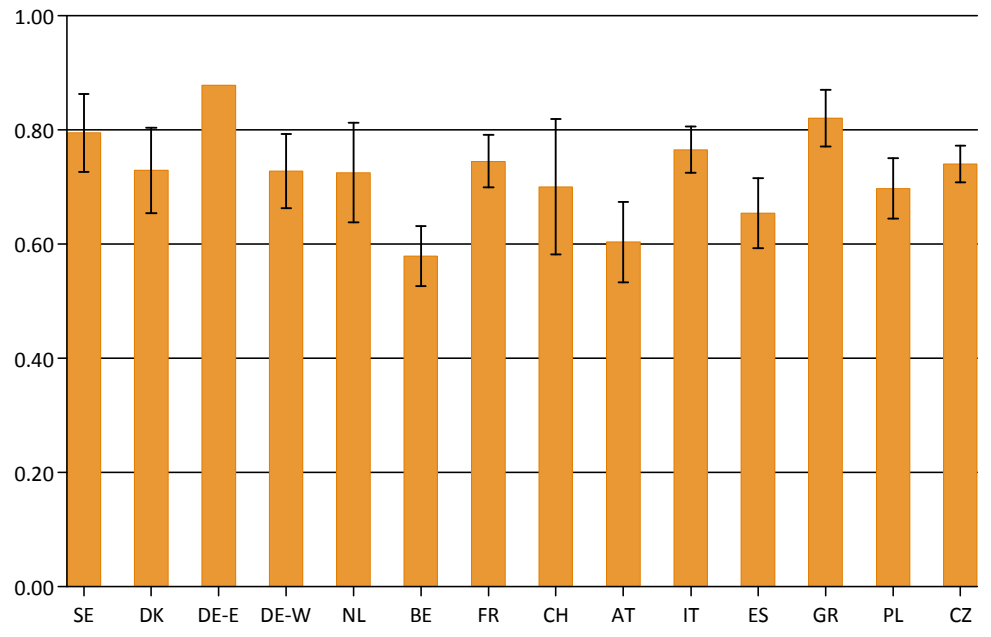

Figure 11.4b: Replacement rate by gender

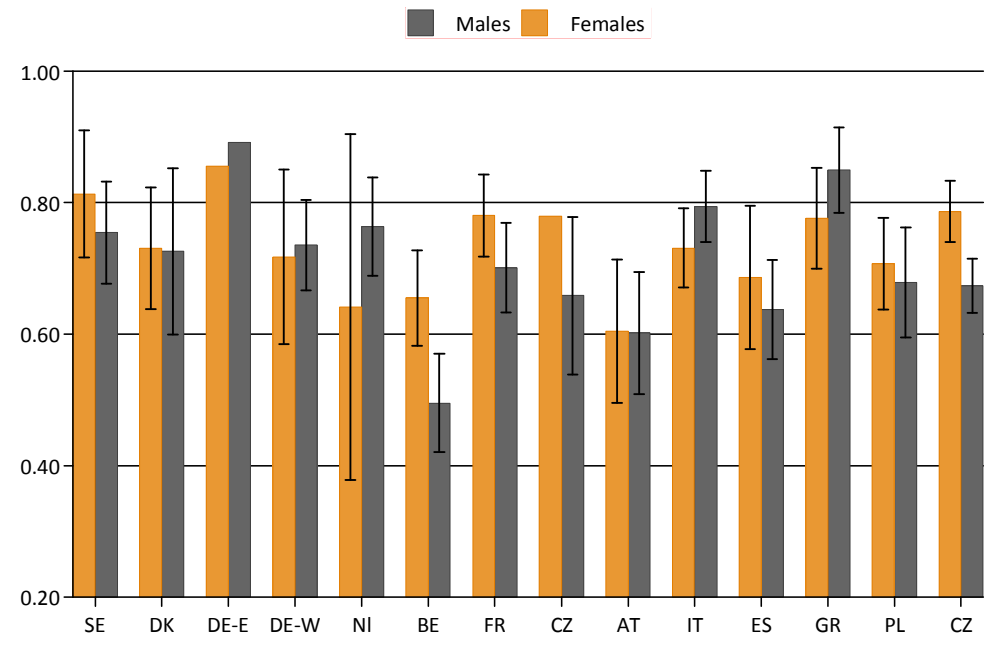

Note: confidence intervals whose upper bound exceed 1 and are not reported in the figure

Figure 11.4c: Replacement rate by cohort 


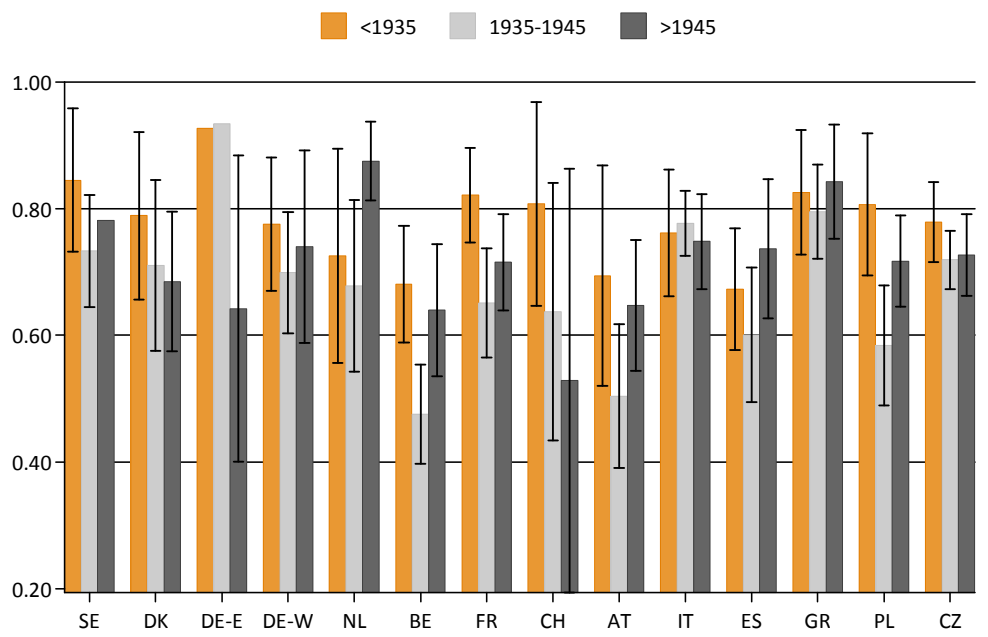

Note: confidence intervals whose upper bound exceed 1 and are not reported in the figure

Figure $11.4 \mathrm{a}$ shows the average replacement rate (the average of individual replacement rates). For most countries it ranges between 0.70 and 0.80, with Austria, Belgium and Spain featuring a lower rate, and East Germany and Greece a slightly higher rate. In figures $11.4 \mathrm{~b}$ and $11.4 \mathrm{c}$ the observations are grouped by gender and year of birth. Changes in institutional arrangements which affect the generosity of the pension system may in principle lead to gender and cohort differences within countries. We find that these differences are not statistically significant.

Given the large heterogeneity of replacement rates across countries, it is important to understand to what extent the observed differences correlate with differences in number and duration of employment and unemployment spells.

Figure 11.5: Replacement rate and number and duration of long employment spells 


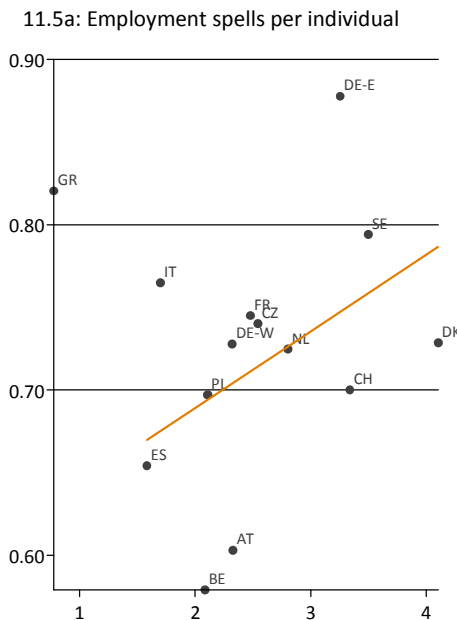

$11.5 \mathrm{~b}$ : Job tenure per individual

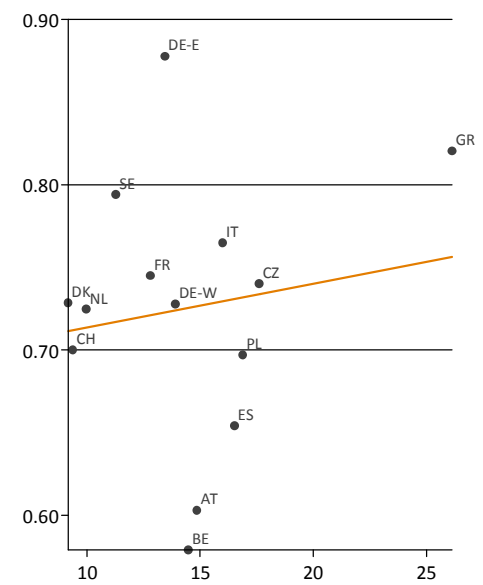

Figures $11.5 \mathrm{a}$ and $11.5 \mathrm{~b}$ show the relation between the replacement rate and the number and duration of employment spells respectively. The straight line is the regression line fitted to the data. Because East Germany and Greece appear as outliers, we include them in the scatter plot but not in the fitted regression lines. Figure 11.5a reveals a positive relation between the number of employment spells and the replacement rate. This may be due to the fact that, as we have already shown, most of the job changes are job-to-job transitions. Therefore, a higher number of employment spells may signal a faster career and a higher contribution accrual, rather than a difficulty in retaining a job. By the same token, a longer tenure does not have any statistically significant effect on replacement rates (see figure 11.5b): as long as most of the job changes are job-to-job movements, there is no reason to expect the average duration of an employment spell to matter in terms of pension rights.

Figure 11.6: Replacement rate and number and duration of long unemployment spells 

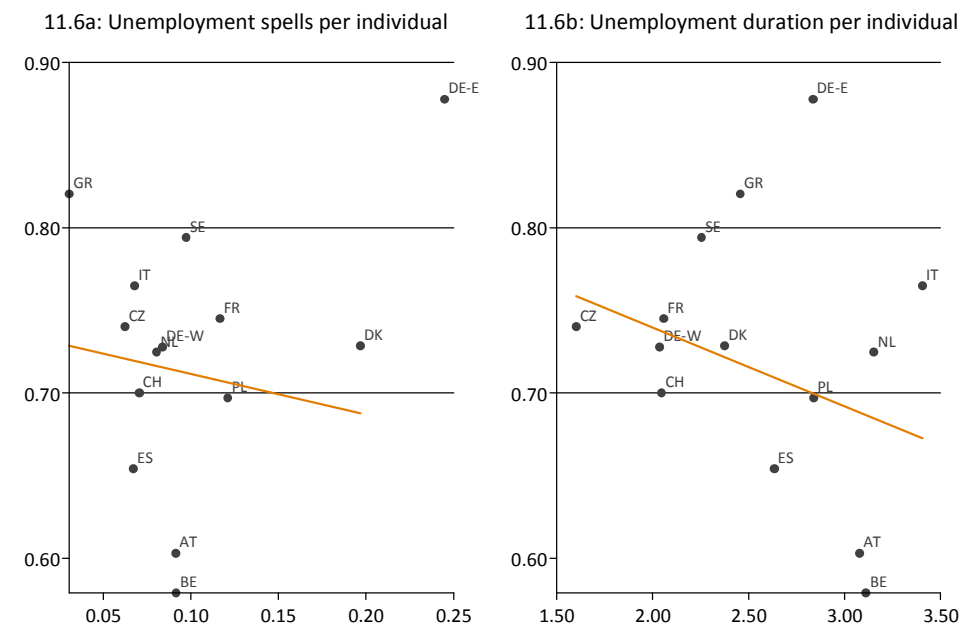

Figures 11.6a and 11.6b show the scatter plots of the average number and the average duration of long unemployment spells by country against the average replacement rate. Although we include the observation for East Germany in the scatter plot, we exclude this country from the regression line, because its high average number of unemployment spells may just be due to the very small sample size. The figures reveal a clear negative relationship between the replacement rate and the number as well as the duration of long unemployment spells. Countries characterized by work history with many and long unemployment spells tend to exhibit lower replacement rates.

Figure 11.7: Replacement rate and legal old age pension at the moment of retirement 


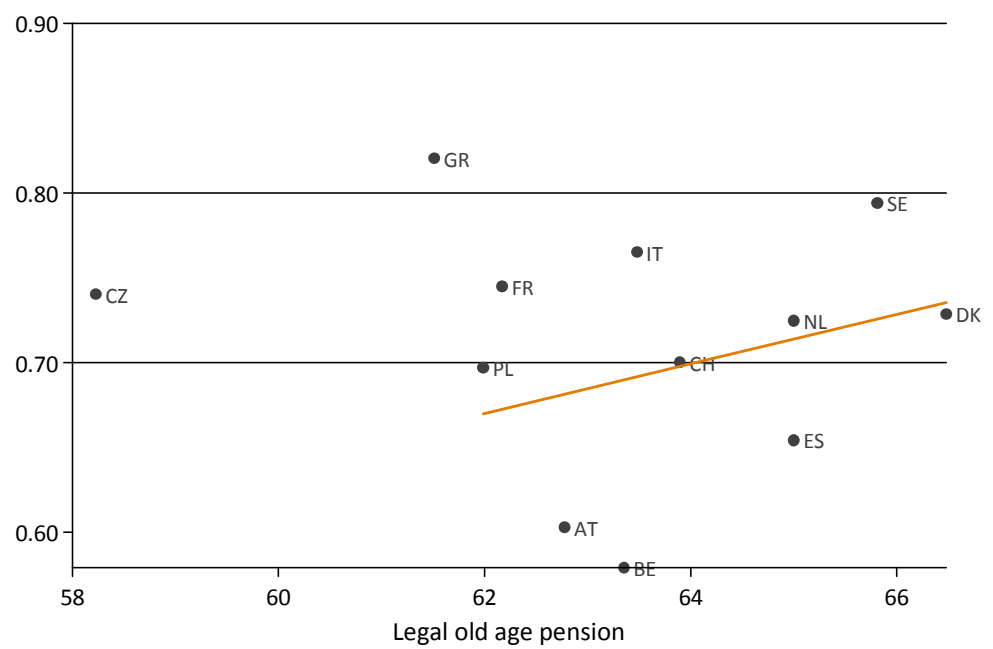

Finally, Figure 11.7 relates the actual average replacement rate of each country with the average legal retirement age prevailing at the time of retirement in the sample. Once again we exclude Greece and the Czech Republic from the regression line because the institutional data about the past legal retirement age and also about the actual replacement rate show some inconsistencies. The legal retirement age for old age pension is the country-average of the legal retirement age for each individual at the time of her retirement, which is meant to emphasize the role of institutions through the "exogenous" legal retirement age. The positive association between the actual replacement rate and the legal retirement age suggests that in those countries where people are induced to work longer (higher retirement age) they also achieve higher replacement rates. This result might be due to both a "formula" effect, i.e. it might depend directly on the way the length of the career enters the benefit calculation and a "filling" effect, i.e. individuals who have the opportunity to work longer may fill the contributions gaps due to unemployment spells.

\subsection{Conclusions}

The patterns of job mobility vary greatly across European countries. The number of jobs held during a career by the average worker is much higher in Northern than in Southern countries. The available evidence points into the same direction: labour markets in Southern countries are much less mobile than in Northern countries. However, cross-country differences in job mobility do not translate into corresponding cross-country differences in replacement rates. On the other hand, pen- 
sion entitlements appear to be very sensitive to the number and duration of unemployment spells in the workers' careers.

Our results suggest that labour mobility, if anything, positively affects the replacement rate, and that institutions which help keep unemployment spells short, for example through active labour market policies, also reduce differences between less and more mobile workers. Therefore, the current tendency to deregulate European labour markets is not necessarily detrimental for income after retirement, provided it is tempered by policies designed to limit long-term unemployment.

\section{References}

Angelini V., Brugiavini, A. and Weber, G. (2009). Ageing and Unused Capacity in Europe: Is There an Early Retirement Trap? Economic Policy, Vol. 59, pp. 463-508.

Boeri, T. and Brugiavini, A. (2009). Pension Reforms and Women Retirement Plans. Journal of Population Ageing, Vol. 1, pp. 7-30.

Brugiavini, A. and Peracchi, F. (2005). The Length of Working Lives in Europe. Journal of the European Economic Association, Vol. 3, pp. 477-486.

Brugiavini, A., Pasini, G. and Peracchi, F. (2008). Exits from the Labour Force, in A. BörschSupan, A. Brugiavini, Hendrick Jürges, Arie Kapteyn, Joahn Mackenbach, Johannes Siegrist, Guglielmo Weber (eds.), Health, Ageing and Retirement in Europe (2004-2007), Starting the Longitudinal Dimension (pp. 204-212), Mannheim: MEA.

Gustman, A. and Steinmeier, T. (1993). Pension portability and labor mobility: Evidence from the survey of income and program participation. Journal of Public Economics, Vol. 50, pp. 299-323.

Peracchi, F. and Welch., F. (1994). Trends in labor force transitions of older men and women. Journal of Labor Economics, Vol. 12, pp. 210-242. 